\title{
REVIEW
}

\section{Current Perspectives on Interferon Beta-1b for the Treatment of Multiple Sclerosis}

\author{
Martin Marziniak $\cdot$ Sven Meuth
}

To view enhanced content go to www.advancesintherapy.com Received: July 21, 2014 / Published online: September 3, 2014

(C) The Author(s) 2014. This article is published with open access at Springerlink.com

\section{ABSTRACT}

Interferon (IFN) beta-1b was the first diseasemodifying therapy to be approved for the treatment of multiple sclerosis (MS), and over 21 years of follow-up data demonstrate its efficacy and long-term safety profile. Following recent regulatory approvals in the USA and European Union, IFN beta-1b is now one of the seven disease-modifying therapies [intramuscular IFN beta-1a; subcutaneous (SC) IFN beta-1a; IFN beta-1b SC; glatiramer acetate SC; oral dimethyl fumarate; oral teriflunomide; and intravenous alemtuzumab] indicated for first-line use in relapsing-remitting MS. Here we review the clinical trial and follow-up data for IFN beta- $1 \mathrm{~b}$ and discuss factors that clinicians may consider when selecting this treatment,

Electronic supplementary material The online version of this article (doi:10.1007/s12325-014-0149-1) contains supplementary material, which is available to authorized users.

M. Marziniak

kbo-Isar-Amper-Klinikum München-Ost, Haar, Germany

\section{S. Meuth $(\square)$}

Institut für Physiologie, Albert-Schweitzer

Campus 1, Münster, Germany

e-mail: sven.meuth@ukmuenster.de both at first line in early MS, and later in the disease course.

Keywords: Autoinjector; Clinically isolated syndrome; Clinical trial; Disease-modifying therapy; Multiple sclerosis; Neurology; Relapsing-remitting; Secondary-progressive; Safety; Tolerability

\section{INTRODUCTION}

Typically, multiple sclerosis (MS) manifests clinically as relapses and disability progression, and subclinically as disease activity in the form of white-matter lesions and brain atrophy $[1,2]$. The earliest description of MS is dated to the fourteenth century and disease-modifying therapy (DMT) remained in the 'dark ages' until approval in 1993 of the first interferon (IFN) treatment for relapsing-remitting MS (RRMS) [3].

Injected every other day (EOD) subcutaneously (SC), IFN beta-1b (Betaseron ${ }^{\circledR}$ in the USA, Betaferon ${ }^{\circledR}$ in Europe; Bayer) was joined in 1996 by IFN beta-1a (Avonex ${ }^{\circledR}$; Biogen Idec), which requires intramuscular (IM) 
injection weekly. A second IFN beta-1a $\left(\right.$ Rebif $^{\circledR}$; Merck Serono), which is injected three times a week SC, gained approval in 2002, only after head-to-head comparison with Avonex in the Evidence of Interferon Dose-ResponseEuropean North American Comparative Efficacy (EVIDENCE; ClincalTrials.gov \#NCT00292266) trial [4]. Extavia ${ }^{\circledR}$ (Novartis), launched in 2009, uses the same biological ingredient (IFN beta-1b) and administration route as Betaseron. Initially approved for relapsing MS or RRMS, the indications for both IFN beta-1b and beta-1a were expanded following a series of clinical trials [5-11], to include clinically isolated syndromes (CIS) and secondary-progressive MS (SPMS) with relapses.

Glatiramer acetate (GA; Copaxone ${ }^{\circledR}$, Teva), a synthetic polymer of four amino acids injected SC, underwent a similar development process, the original 1996 license for relapsing forms of MS later being extended to include CIS [12]. Also, an increased-dose regimen with reduced frequency of administration was recently approved for GA [13]. As well as the injectable therapies that have a long history of use as first-line treatments (Betaseron, Rebif, Avonex, Copaxone, Extavia-'BRACE'), several intravenous or oral therapy options have become available in recent years: natalizumab (Tysabri $^{\circledR}$; Biogen Idec, initially 2004, then 2006 following temporary withdrawal for safety review); alemtuzumab [Lemtrada ${ }^{\circledR}$; Sanofi, 2013-European Union (EU) only]; fingolimod (Gilenya ${ }^{\circledR} ; \quad$ Novartis, 2010-different indications in the USA and the EU); teriflunomide $\left(\right.$ Aubagio $^{\circledR}$; Sanofi, 2012), and dimethyl fumarate (DMF; Tecfidera ${ }^{\circledR}$; Biogen Idec, 2013) [14].

As one of the mainstays of the BRACE therapies, self-administered, high-dose, highfrequency (i.e., $250 \mu$ g EOD) IFN beta-1b has a long-standing efficacy and safety profile, and remains a first-line option for many patients with MS [15, 16]. Since the introduction 21 years ago of IFN beta-1b, the process of selfadministration has also evolved from a simple hypodermic kit to autoinjection devices that standardize and facilitate delivery of therapy. The benefits of autoinjection are evident not only in patients' preferences for the technology, but also in improved tolerability of, and adherence to, treatment [17-21].

Here, we review clinical evidence that neurologists may consider when contemplating IFN beta-1b as first-line therapy in MS, patient groups in which IFN beta-1b treatment may be particularly appropriate, and considerations when change of therapy is indicated for reasons of adherence, tolerability or disease control. This review article is based on previously conducted studies, and does not involve any new studies of human or animal subjects performed by any of the authors.

\section{HIGH-DOSE, HIGH-FREQUENCY IFN BETA- $1 b$ THERAPY AND BENEFITS OF EARLY TREATMENT}

As well as being the first DMT approved for MS in the USA (1993) [22] and EU (1995) [23], postapproval exposure amounting to 1.3 million patient-years has confirmed the long-term safety and tolerability of IFN beta- $1 b[20,24]$. In the $\mathrm{EU}$, the initial treatment indication for IFN beta-1b has been extended from RRMS and this label now includes early and later stages of disease [25].

- CIS: patients with a single demyelinating event with an active inflammatory process, if it is severe enough to warrant treatment with intravenous corticosteroids, if alternative diagnoses have been excluded, and if they are determined to be at high risk of 
developing clinically definite multiple sclerosis (CDMS).

- RRMS: patients with RRMS and two or more relapses within the last 2 years.

- SPMS: patients with SPMS with active disease, evidenced by relapses.

\section{Clinically Isolated Syndromes}

The 2-year Betaferon in Newly Emerging Multiple Sclerosis for Initial Treatment (BENEFIT; ClincalTrials.gov \#NCT00185211) study was the pivotal phase 3 trial of IFN beta$1 \mathrm{~b}$ in patients with CIS, comparing the efficacy, safety, and tolerability of IFN beta- $1 \mathrm{~b}$ with placebo [6]. In total, 487 patients were enrolled at 98 centers in Europe, Canada, and Israel into an initial double-blind, parallelgroup phase in which patients were randomized 5:3 to IFN beta-1b $250 \mu \mathrm{g}$ SC EOD or to matching placebo injections. Early IFN beta-1b therapy significantly delayed conversion to MS, irrespective of the endpoint used; benefits were seen after only a few months with the McDonald criteria [26], and conversion to CDMS according to the Poser criteria [27] was delayed by $\sim 1$ year $[5,6]$. Kaplan-Meier estimates indicate that the cumulative probability of developing CDMS was reduced from $45 \%$ in the placebo group to $28 \%$ in the IFN beta-1b group, representing an absolute risk reduction of $17 \%$; respective rates of development of McDonald MS were $85 \%$ and $69 \%$, a risk reduction of $16 \%$. Compared with placebo, the relative risk of conversion to CDMS was reduced by $50 \%$ [hazard ratio (HR) 0.50 ; 95\% confidence interval (CI) 0.36-0.70]. Similarly, the relative risk of conversion to McDonald MS was reduced by $46 \%$ (HR 0.54; 95\% CI 0.43-0.67) [6].

The delay in conversion was also apparent in patient subgroups defined according to measures of clinical and magnetic resonance imaging (MRI) disease activity at onset. Consistent with findings reported for other DMTs $[7,11]$, there was a trend showing that the benefits were greater in patients with less advanced disease than in those with more advanced disease at baseline [i.e., monofocal manifestation, absence of gadoliniumenhancing $(\mathrm{Gd}+)$ lesions, fewer than nine $\mathrm{T} 2$ lesions], underscoring the importance of early treatment with immunomodulatory therapies in patients with CIS [6]. IFN beta-1b prevented the development of new inflammatory brain lesions and reduced the burden of disease (T2 lesion volume and count) in patients with a first event suggestive of MS [6].

Patients completing the placebo-controlled phase of the BENEFIT study were eligible to enter a prospectively planned follow-up phase and subsequent observational extension, in which patients were observed for up to 8.7 years $[5,28]$. All patients who entered the extension were given the option of treatment with IFN beta-1b, an alternative DMT, or no medication. The benefits of early therapy were still evident after 8 years, as patients initially randomized to IFN beta- $1 \mathrm{~b}$ treatment had a significantly lower risk of CDMS compared with those in whom treatment was delayed by 2 years [28]. Kaplan-Meier estimates indicate that $55.5 \%$ of patients randomized to IFN beta$1 \mathrm{~b}$ treatment had progressed to CDMS compared with $65.8 \%$ of patients in the delayed-therapy group $(P=0.0029)$. Compared with the delayed-treatment group, the relative risk of conversion to CDMS was reduced by $32 \%$ (HR 0.68; 95\% CI 0.53-0.88; $P=0.0029$ ) and time to CDMS was postponed by 3.7 years (50th percentile) [28]. Annualized relapse rate (ARR) was a key outcome measure of the extension study, and relapse outcomes significantly favored early IFN beta-1b therapy. Over 
8 years, compared with patients in whom therapy was delayed, patients randomized to IFN beta- $1 b$ had a lower ARR (0.26 versus 0.20 , respectively; $P=0.0012$ ), representing a $23 \%$ reduction in risk (HR 0.77; 95\% CI 0.66-0.90; $P=0.0012$ ). Disability, assessed by the Expanded Disability Status Scale (EDSS) and MS Functional Composite scale scores, remained low and stable in both groups throughout the 8 years of study, however patients randomized to IFN beta- $1 \mathrm{~b}$ had higher (i.e., improved) scores on the Paced Auditory Serial Addition Test (PASAT) used for cognitive assessment $(P=0.0453)$. This low rate of disability progression was attributed to early treatment, as patients in both arms received DMT within 2 years of CIS, which is still quite early in the disease course [28].

\section{Relapsing-Remitting Multiple Sclerosis}

The 2-year Interferon Beta-1b (IFNB) study was the pivotal phase 3 trial of IFN beta- $1 \mathrm{~b}$ in patients with RRMS and compared the efficacy, safety and tolerability of IFN beta-1b and placebo [29]. The study comprised two identically designed trials conducted in the USA and Canada. A total of 372 patients at 11 centers were enrolled in the double-blind, parallelgroup studies, and were randomized 1:1:1 to placebo, IFN beta-1b $50 \mu \mathrm{g}$ SC EOD or IFN beta$1 \mathrm{~b} 250 \mu \mathrm{g}$ SC EOD. However, the findings discussed here are those associated with the $250 \mu \mathrm{g}$ dose, which subsequently received regulatory approval [22, 23]. All patients completing the study could participate in a double-blind, placebo-controlled, extension phase of up to 3.5 years; data collected after the first year of the extension were reported as 3-year data. The IFNB study met both primary endpoints, demonstrating at 2 years that IFN beta- $1 \mathrm{~b}$ reduced ARR compared with placebo
(0.84 versus 1.27 , respectively; $P=0.0001)$ and increased the proportion of exacerbation-free patients $(31 \%$ versus $16 \%$, respectively; $P=0.007)$. At 3 years, ARR was still lower in patients receiving IFN beta- $1 \mathrm{~b}$ compared with placebo (0.84 versus 1.21, respectively; $P=0.0004)$ and the proportion of exacerbation-free patients was still higher, but not significantly (22\% versus $14 \%$, respectively; $P=0.097)$. Further measures showed that IFN beta- $1 \mathrm{~b}$ halved the annual rate of moderate and severe relapses compared with placebo over 2 years $\quad(0.23$ versus 0.45 , respectively; $P=0.002$ ) and reduced the number of hospitalizations over 3 years (37 versus 65, respectively; $P=0.046$ ). Levels of disability during the study were stable among the majority of patients treated with IFN beta- $1 \mathrm{~b}$ (80\%) and placebo (72\%); no between-group difference was observed $(P=0.161)$ [29].

Assessment of lesion burden (total lesion area estimated by MRI) at 3 years, found a median reduction from baseline of $9.3 \%$ associated with IFN beta-1b, compared with an increase of $15.0 \%$ with placebo $(P=0.002)$. Acute lesion activity was also reduced by IFN beta-1b compared with placebo. A cohort of 52 patients underwent MRI scans every 6 weeks during the first 2 years of the study, and the median annual rate of active lesions (defined as new, recurrent or enlarging) was $83 \%$ lower in the IFN beta-1b group than the placebo group (annual rate: 0.5 and 3.0, respectively; $P=0.0089$ ). Similarly, the median annual rate of new lesions was $75 \%$ lower with IFN beta-1b than with placebo (annual rate: 0.5 and 2.0, respectively; $P=0.0026$ ) [30].

Among correlation analyses conducted 16 years after randomization, the relationships between long-term cognitive outcomes and clinical and MRI characteristics reported at baseline or during the IFNB trial were examined 
[31]. Cognitive outcomes were assessed using a 'Cognitive Performance Index' (the sum of a patient's $z$ scores from PASAT, the Symbol Digit Modality Task, the California Verbal Learning Test II, the Controlled Oral Word Association Task, and the Delise-Kaplan Executive Function System test). Significant correlations were seen between cognitive outcome and baseline EDSS $(R \quad 0.12 ; P<0.0001)$ and baseline $\mathrm{T} 2$ lesion burden $(R \quad 0.21 ; \quad P<0.0001) . \quad$ Multivariate regression analysis demonstrated that outcomes during the trial contributed little to prediction of long-term outcomes [31].

At 21.4 years, the reported follow-up of IFN beta-1b is the longest for any MS therapy. A long-term cohort study has evaluated the effects of early treatment with IFN beta-1b on all-cause mortality in patients with RRMS who participated in the IFNB study. At a median of 21.1 years after the time of enrolment in the original study, 366 of 372 patients (98.4\%) were identified; of these, 81 (22.1\%) had died. At 21 years there was a $47 \%$ reduction in the cumulative risk of death (HR 0.53; 95\% CI 0.31-0.90; $\quad P=0.0173$ ) among patients receiving IFN beta- $1 \mathrm{~b}$ during the first 2 years compared with those initially randomized to placebo [32]. This treatment effect could have been attributable to an unexpectedly high mortality rate in the placebo group, but the 29-year survival rate in this group was shown to be very similar to that seen in a natural history MS population from Norway [33].

Sensitivity analyses assessed the robustness of the results of the 21-year follow-up study, including assessment of mortality data from onset of clinical symptoms, rather than from randomization: IFN beta-1b was associated with a 50\% reduction in all-cause mortality risk compared with placebo (HR 0.50; 95\% CI $0.29-0.85 ; P=0.0089)$. It is difficult to explain such a long-term effect based on treatment differences in the first 2 years of study, and it is notable that in the 16-year follow-up population [34], median exposure to IFN beta$1 \mathrm{~b}$ was greater among patients initially randomized to IFN beta-1b (8.9 years; range $0.1-17.1$ years) than in those initially assigned to placebo (5.0 years; range $0-12.5$ years) [32]. The investigators indicated that they could not "distinguish between the possibility that the observed survival benefit was due to an effect of early treatment and the possibility that the benefit was due to longer duration of interferon beta-1b exposure" [32]. There are confounding factors to consider: although a very high proportion of patients who enrolled in the IFNB study were identified at the 21-year follow-up, a relatively high proportion of those enrolled had discontinued treatment during the 2-year study [17\% (65/372)] and more than 100 patients failed to complete the first year of the study extension [29]. In addition, the primary endpoint of the study examined all-cause mortality rather than death attributable to MS [32], although a subsequent analysis established that $67 \%$ of the 81 recorded deaths were MS-related. Information about treatment subsequent to IFNB was unavailable for approximately one third of patients at the 16-year follow-up, although it should be noted that IFN beta-1b was the only MS DMT available until 1996, and that the demography of the patients in the 16-year follow-up was representative of the original trial population [34]. Finally, information about treatment was unavailable for the majority of patients in the last 5 years of the 21-year follow-up, although this was not an objective of the analysis [32, 35].

\section{Secondary-Progressive Multiple Sclerosis}

Pivotal phase 3 studies of IFN beta- $1 b$ versus placebo have been undertaken in patients with 
active relapsing SPMS in both Europe [8] and North America [36]. The primary endpoint in both studies was time to disability progression over 3 years. Although this was prolonged by more than 200 days in both studies among patients receiving IFN beta- $1 \mathrm{~b}$ compared with placebo, the difference was only significant in the European study $(P<0.001)[8,36-39]$. In both studies, compared with placebo, IFN beta$1 \mathrm{~b}$ reduced ARR over 3 years and prolonged time to first relapse by more than 200 days $(P \leq 0.01$, all comparisons) $[8,36]$.

The European study was a double-blind, parallel-group trial in which patients were randomized $1: 1$ to placebo or IFN beta-1b $(250 \mu \mathrm{g}$ SC EOD). In total, 718 patients were enrolled in 32 European centers, and the study met its primary endpoint, demonstrating that over 3 years, IFN beta- $1 \mathrm{~b}$ prolonged time to disability progression compared with placebo in both the prospective interim, and final analyses $(P=0.0008 ; P=0.007$, respectively) $[8,37]$. The final analysis of the study showed that IFN beta- $1 \mathrm{~b}$ reduced mean ARR over 3 years compared with placebo $(0.42$ and 0.57 , respectively; $P=0.003$ ), and other prospective and post hoc analyses reported increases in the proportion of patients who remained relapsefree or experienced a decrease in relapse rate (53.1\% versus $45.0 \%$, respectively; $P=0.031$ ); increases in the proportion of patients remaining relapse-free, or who either remained relapse-free or experienced a decrease in relapse severity, were not significant $(P=0.083$; $P=0.152$, respectively) [37].

Examining MRI measures in the European study, there was no difference in total lesion volume between the IFN beta-1b and placebo groups at baseline $(P=0.4117)$. However, IFN beta- $1 \mathrm{~b}$ treatment was associated with reductions in total lesion volume from baseline at all time points measured during the study, whereas placebo was associated with increases from baseline $(P<0.0001$, for all between-group comparisons). At the last MRI scan, the percentage change in mean total lesion volume from baseline in the two treatment groups was $-2.1 \%$ and $15.4 \%$, respectively $(P<0.0001)$. In a cohort of patients who underwent monthly MRI scans $(n=125)$, the mean cumulative number of both newly and persistently active lesions associated with IFN beta-1b treatment was lower than with placebo. During months 19-24, IFN beta-1b treatment was associated with a $78 \%$ reduction in newly active lesions $(P=0.0008)$, and an $88 \%$ reduction in persistently active lesions $(P=0.0004)$ [38].

In the North American study of patients with SPMS, patients were randomized 1:1:1 to receive IFN beta-1b $250 \mu \mathrm{g}$ SC EOD, IFN beta-1b $160 \mu \mathrm{g} / \mathrm{m}^{2}$ (body surface area) SC EOD, or placebo. The primary endpoint was not met at either dose of IFN beta-1b; when considering the approved dose of $250 \mu \mathrm{g}$, the time taken for 6-month disability progression to be confirmed among $30 \%$ of patients in the placebo groups (750 days) and IFN beta-1b group (981 days) was not significantly different $(P=0.606)$ [36]. This finding was unaffected by adjustments for center, baseline EDSS score and duration of disease. Also, no between-group difference was seen in the change in mean EDSS score from baseline to the end of study $(P=0.634)$ [36].

Differences in disability outcomes between the European and North American studies in SPMS may be related to differences in eligibility criteria and methods of EDSS assessment. Although the definition of confirmed disability progression was more stringent in the North American study (requiring a period of 6 months before progression could be confirmed rather than the 3 months in the European study), post hoc application of the more stringent definition 
to the European data still showed that IFN beta$1 \mathrm{~b}$ offered significant improvements versus placebo in that study.

It is possible that patients in the North American study were in a more progressive and less inflammatory stage of disease and therefore showed a less robust response to IFN beta-1b than patients in the European study [36]. However, in a post hoc, retrospective meta-analysis of the North American and European trials, there was an overall risk reduction of about $20 \%$ associated with IFN beta-1b $250 \mu \mathrm{g}$ SC EOD compared with placebo for EDSS progression confirmed at 6 months $(P=0.008)$. The meta-analysis also indicated that the unexpected disparity between the studies in disability progression outcomes was due to differences in patients' baseline disease activity [39].

Beneficial effects on various relapse-related endpoints were associated with IFN beta-1b $250 \mu \mathrm{g}$ SC EOD compared with placebo over 3 years in the North American study: ARR was $43 \%$ lower (0.16 versus 0.28 , respectively; $P=0.009)$; there was a lower rate of moderate or severe relapses ( 0.10 versus 0.19 , respectively; $P=0.010)$; a smaller proportion of patients had moderate or severe relapses $(21 \%$ versus $30 \%$, respectively; $P=0.012$ ); time to first relapse was greater (1,051 days versus 487 days to the $30 \%$ quantile; $P=0.010)$; and a greater proportion of patients were relapse free (71\% versus $62 \%$, respectively; $P=0.018$ ) [36]. Annual MRI data from the North American study were consistent with the European study; mean increase in T2 lesion area associated with IFN beta-1b $250 \mu \mathrm{g}$ SC EOD was lower than with placebo (107 versus $\left.637 \mathrm{~mm}^{2} ; P<0.001\right)$, and in a frequentscan cohort $(n=163, \mathrm{Gd}+$ scans every 4 weeks for 3 years), the annual new active lesion rate was lower in the IFN beta-1b group than the placebo group (6.4 versus 18.7, respectively; $P=0.003)[36]$.

\section{HEAD-TO-HEAD STUDIES OF IFN BETA-1b AND OTHER BRACE THERAPIES}

Relatively few head-to-head studies have been conducted among the BRACE therapies and discussion here is confined to those involving IFN beta-1b: versus IFN beta-1a IM, the Independent Comparison of Interferons (INCOMIN) trial [40]; versus IFN beta-1a SC [41]; versus IFN beta-1a both IM and SC [42]; and versus GA, the Betaferon Efficacy Yielding Outcomes of a New Dose (BEYOND; ClinicalTrials.gov \#NCT00099502) trial [43] and the Betaseron versus Copaxone in Multiple Sclerosis with Triple-Dose Gadolinium and 3-Tesla MRI Endpoints (BECOME; ClinicalTrials.gov \#NCT00176592) trial [44].

Conducted over 2 years in patients with RRMS, the INCOMIN trial compared the efficacy, safety, and tolerability of high-dose, high-frequency IFN beta-1b (250 $\mu$ g SC EOD) with that of low-dose, low-frequency IFN beta1a (Avonex; $30 \mu \mathrm{g}$ administered IM once a week). In total, 188 patients were enrolled at 15 centers across Italy, and the primary endpoint was the proportion of patients who were relapse-free during the study. Secondary clinical outcomes included: ARR; the proportion of patients free from confirmed disability progression; time to confirmed disability progression; and EDSS score [40]. For the majority of clinical measures, IFN beta- $1 \mathrm{~b}$ was superior to IFN beta-1a IM. Comparing these two treatment arms, respectively: the proportion of patients who were relapse-free was greater over 2 years (51\% versus 36\%; $P=0.03)$; the relative risk of relapse was 
reduced by $24 \%$ (HR 0.76 ; 95\% CI $0.59-0.99$; $P=0.03)$ and mean ARR was reduced ( 0.5 versus $0.7 ; P=0.03)$; confirmed disability progression (sustained for 6 months, assessed over 2 years using the EDSS) was lower (13\% versus 30\%; $P=0.005)$; the relative risk of disability progression was reduced by $56 \%$ (HR 0.44; 95\% CI $0.25-0.80 ; \quad P=0.005)$; time to confirmed disability progression was prolonged $(P<0.01)$; and mean EDSS score at 2 years was lower (2.1 versus $2.5 ; P=0.004)$ [40]. Similarly, IFN beta-1b was superior to IFN beta-1a IM across all MRI measures of inflammatory activity over 2 years. Respectively: the proportion of patients free from new T2 lesions was greater (55\% versus $26 \% ; P<0.001)$; the proportion of patients free from $\mathrm{Gd}+$ lesions was greater (76\% versus $49 \%$; $P=0.001)$; and the proportion of patients free from any MRI activity was greater (51\% versus 25\%; $P<0.001$ ). In addition, treatment with IFN beta-1b showed superiority over IFN beta-1a IM for these MRI measures over the interim 1-year intervals (months 0-12 and 13-24). Finally, at 2 years there was a mean decrease from baseline in the burden of disease (total T2 lesion volume) associated with IFN beta-1b treatment, and a mean increase associated with IFN beta-1a treatment $(-2.8 \%$ versus $11.7 \% ; \quad P<0.0001)$ [40]. When considering these findings, it should be borne in mind that this study was not conducted double-blind, although the authors state that a centralized randomization process guarded against selection bias and MRI-scan readers were blinded to patients' treatment allocation. Also, the fact that all clinical outcomes were assessed under open-label conditions placed this study at high risk of interpretive bias [45].

A subsequent study comparing high-dose, high-frequency and other regimens was conducted by the Danish Multiple Sclerosis
Group [41]. It was a multicenter, open-label, randomized 2-year trial in 301 patients with RRMS comparing IFN beta-1a $22 \mu \mathrm{g}$ SC once a week $(n=143)$ with IFN beta-1b $250 \mu$ g SC EOD $(n=158)$. The trial also included a cohort of patients $(n=120)$, who had declined to be randomized and received IFN beta-1b $250 \mu \mathrm{g}$ SC EOD. Among the randomized patients, no between-group differences were seen in the primary endpoints of ARR $(-0.01 ; 95 \%$ CI -0.15 to 0.13 ) and time to first relapse (IFN beta-1a versus IFN beta-1b: HR 0.98; 95\% CI 0.72-1.32), neither was there a between-group difference in time to sustained disability progression ( $\geq 1$.0-point increase in EDSS score, secondary endpoint: HR 0.91; 95\% CI 0.56-1.45) [41]. The lack of a double-blind design increased the risk of bias as did the fact that losses to follow-up were not included in the analysis [45]. Technical difficulties precluded reporting of a fairly substantial proportion of the MRI data from this study. No significant between-group differences were seen at baseline in mean new/enlarged T2 lesion area $(P=0.39)$, or in the mean increase of new/enlarged T2 lesion area from baseline to month 12 $(P=0.099)$, or from month $12-24(P=0.078)$. Subjectively, the mean increase in lesional area associated with IFN beta-1a treatment was greater than with IFN beta-1b and a similar trend was reported comparing the respective proportions of patients with 'active scans' (either new or enlarging T2 lesions compared with a previous study scan or the presence of $\mathrm{Gd}+$ lesions $)$ at 2 years $(P=0.061)$.

The clinical and MRI efficacy of IFN beta-1b and GA have been compared in patients with RRMS in the phase 3 BEYOND trial [43]. In this trial, 2,244 patients from 26 countries were randomized $2: 2: 1$ to IFN beta-1b $250 \mu \mathrm{g}$ SC EOD, IFN beta-1b $500 \mu \mathrm{g}$ SC EOD or GA $20 \mathrm{mg}$ SC daily and followed for up to 3.5 years. At 
2 years, no significant differences in clinical outcomes (risk of relapse, ARR, proportion of relapse-free patients, and time to confirmed disability progression) or most MRI measures (including mean change in T1-hypointense lesion volume, and mean change in brain volume from baseline) were observed between any two treatment groups [43]. Further, compared with patients receiving GA, the rate of evolution of new lesions into permanent black holes (a marker of irreversible disease) was similar among those receiving the approved dose of IFN beta-1b but some benefit was seen among those receiving the $500 \mu \mathrm{g}$ dose of IFN beta-1b $(P=0.0409)$ [46]. Although no clear advantage in terms of efficacy was associated with either treatment, this study does support the notion that there is little therapeutic benefit associated with IFN beta-1b dosing at $500 \mu \mathrm{g}$ instead of $250 \mu \mathrm{g}$ SC EOD in early RRMS. The small, phase 4 BECOME trial also compared IFN beta-1b with GA [44], enrolling treatment-naïve patients $(n=75)$ with CIS or RRMS in North America. Patients were randomized approximately $1: 1$ to IFN $250 \mu \mathrm{g}$ SC EOD or GA $20 \mathrm{mg}$ SC daily for 1 year, and subsequently given the option of continuing for a second year. A limitation of this study was that, it was only powered to determine differences in MRI rather than clinical outcomes, but in common with BEYOND, few between-group differences in efficacy were observed $[46,47]$.

\section{SAFETY AND TOLERABILITY OF IFN BETA-1b}

The fact that IFN beta- $1 \mathrm{~b}$ has the longest followup period among the approved MS DMTs [32], and that experience of its safety and tolerability is based on over 1.3 million patient-years of exposure [20], provides reassurance for neurologists when considering it as a treatment option. It was generally well tolerated in seven pivotal phase 3 studies spanning patients with CIS [6], RRMS [29, 40, 43], and relapsing SPMS [8, 36]. Summary of the four placebo-controlled phase 3 studies at the approved $250 \mu \mathrm{g}$ dose $[6,8,25,29,36,48]$ revealed the most frequently reported adverse events (AEs) in patients treated with IFN beta- $1 \mathrm{~b}$ $(n=1,407)$ were lymphopenia, injection site reactions (ISRs), asthenia, flu-like symptoms (FLS), complex headache, and pain [25, 48]. The most common laboratory abnormalities were leukopenia and liver enzyme elevations, which infrequently resulted in dose reduction or treatment discontinuation ( $\leq 3 \%$ of patients/ study) [48].

Long-term follow-up of patients 16 years after participation in the phase 3 RRMS study indicated that patients treated continuously with IFN beta-1b for the 2 years prior to the 16-year follow-up visit $(n=69)$ had proportionately fewer treatment-related AEs (including liver enzyme elevations and FLS) than during the first 2 years of the study. Chronic liver disease was not identified in any patient $(n=260)$ throughout the 16 years of follow-up [24]. Another potential side-effect of long-term IFN beta-1b therapy is the production of neutralizing antibodies (nAbs), which inhibit interactions at the cell surface between IFN beta- $1 \mathrm{~b}$ and the type 1 IFN receptor [49]. Occurring in $2-45 \%$ of individuals treated with IFN beta-1b [49], there is a tendency for nAbs to develop within the first year of therapy [29], although a proportion of patients revert spontaneously to seronegative status [50]. The clinical impact of nAbs remains controversial: their presence did not affect conversion to CDMS in the BENEFIT study [5, 28], nor disability progression in various studies of RRMS [40, 50] and SPMS [8, 36], but a negative 
association with MRI measures has been found [50]. The clinical implications of nAbs in MS therapy have been reviewed recently $[49,51]$, but in the absence of specific guideline recommendations, patient management should be guided by clinical response rather than by nAb status.

\section{CONSIDERATIONS IN FIRST-LINE THERAPY SELECTION}

A recent Cochrane review presented a comprehensive meta-analysis of the efficacy of immunomodulatory or immunosuppressive drugs for the treatment of relapsing and progressive forms of MS [45]. The analysis focused on relapse rates and disability progression, but not MRI endpoints, and concluded that there is moderate-quality evidence that IFN beta- $1 b$ limits the recurrence of relapses in RRMS over 2 years of therapy compared with placebo (OR 0.55; 95\% CI 0.31-0.99), and placed a moderate level of confidence in the finding that IFN beta- $1 b$ is more effective than IFN beta-1a IM in reducing the number of individuals with disability progression at 2 years (OR $0.35 ; 95 \%$ CI $0.17-0.70)$. No treatments were found to be effective at limiting disability progression in patients with progressive MS, although IFN beta$1 \mathrm{~b}$ slightly decreased the odds of clinical relapses over 3 years [45]. Compared with placebo, natalizumab and IFN beta-1a SC three times weekly were found to be superior to other treatments in reducing relapse rates in RRMS, and moderate-quality evidence was found for the effectiveness of these two treatments in limiting disability progression [45]. The authors acknowledged that efficacy and benefit/risk conclusions provided in this meta-analysis are uncertain beyond 2 years. Furthermore, despite the fact that relapse rates and disability progression are well-established measures of disease activity, it would be interesting to understand the comparative effects of different treatments on MRI lesion activity, which is commonly assessed in both clinical studies and clinical practice, and which is included in composite measures of disease activity [52].

In addition to the treatments reviewed by Filippini and colleagues [45], the oral treatments teriflunomide $[53,54]$ and DMF [55-57] are now approved in both USA and EU for first-line therapy in MS. Development of these therapies was originally associated with other indications (teriflunomide is the active metabolite of leflunomide, which is indicated in rheumatoid arthritis [58]; DMF is a component of Fumaderm ${ }^{\circledR}$ [Biogen Idec], which is indicated in psoriasis), therefore, there is a reasonably long-standing clinical awareness of possible tolerability issues or side-effects associated with these new first-line therapies that may provide reassurance for their use in MS. However, it should be noted that linomide was associated with unexpected serious AEs in a study of patients with RRMS or SPMS, having been previously well tolerated in other indications [59]. While clinical trials have shown that teriflunomide reduced relapses and delayed disability progression compared with placebo [60, 61], a head-to-head study versus IFN beta-1a SC (TENERE; ClinicalTrials.gov \#NCT00883337) has also shown no superiority of daily teriflunomide versus high-frequency IFN in patients with MS [62]. DMF was approved in 2013 for treatment of relapsing forms of MS $[55,57]$, and has shown significant efficacy compared with placebo (reducing relapses, delaying disability progression and reducing the number of $\mathrm{Gd}+$ and new or enlarged T2weighted hyperintense lesions) [63], although this benefit in delaying disability progression was not seen compared with placebo in the 
2-year, placebo-controlled phase 3 study of DMF and GA (CONFIRM; ClinicalTrials.gov \#NCT00451451) [64].

\section{OVERCOMING THE CHALLENGES OF SELF-INJECTION WITH AUTOINJECTION DEVICES}

The side-effects most frequently reported by patients following self-injection with IFNs are ISRs [18], which typically manifest as mild inflammation, soreness, and pain at the injection site. Erythema and ulceration can also occur, but such reactions are rare if appropriate injection techniques or autoinjection devices are used [18]. Studies have shown that injection site pain (ISP) and ISRs occur significantly more frequently with IFN beta-1a SC than IFN beta-1b SC $[65,66]$. The randomized, phase 4, open-label, crossover EPICURE study compared the occurrence of ISRs when using a standard injection technique compared with an autoinjector in 294 patients with RRMS treated with IFN beta-1b [17]. Over a period of 1 month, the proportion of patients experiencing ISRs was lower with an autoinjector than the standard injection technique $(24.1 \%$ versus $35.9 \% ; P<0.0001)$. The patient- and physician-reported mean ISR intensity was also reduced when an autoinjector was used $(P<0.0001)$. Furthermore, more patients using an autoinjector were ISR-free $(68.1 \%)$ than patients using the standard injection technique (52.4\%).

The Betaseron ${ }^{\circledR}$ versus Rebif ${ }^{\circledR}$ InvestiGating Higher Tolerability (BRIGHT) study was a large international, prospective, observational cohort study that compared the incidence of ISP and ISRs between IFN beta-1b $250 \mu \mathrm{g}$ SC EOD and IFN-beta-1a $44 \mu \mathrm{g}$ SC three times weekly in patients with RRMS $(n=454)$ over a $4-5$ week period [65]. The majority of patients (92\%) used an autoinjector to administer treatment. At all time points over the 15 -injection study period: more patients were pain-free with IFN beta-1b than IFN beta-1a (e.g., $42.6 \%$ versus $19.7 \%$, respectively at $30 \mathrm{~min}$ post-injection; $P<0.0001) ;$ and a greater proportion of injections were pain-free per patient with IFN beta-1b than IFN beta-1a (e.g., 79\% versus $53.3 \%$, respectively at $30 \mathrm{~min}$ post-injection; $P<0.0001)$. In addition, more patients receiving IFN beta-1b than IFN beta-1a had no ISRs $(51.8 \%$ versus $33.8 \% ; P<0.0001)$ after the 15 -injection period. Pain following injection had a negative impact on treatment satisfaction in more patients receiving IFN beta-1a than receiving IFN beta-1b (35.9\% versus $23.1 \%$, respectively; $P=0.006$ ).

Treatment discontinuation rates among patients receiving IFN beta range between 14\% and $44 \%$ [67]. The occurrence of ISRs is a common reported reason for treatment interruption or discontinuation, and presents a barrier to treatment adherence [18, 67-69]; of those who interrupt IFN-beta treatment, ISRs are the reason reported in $12 \%$ of patients [18, 70]. The potential impact of ISRs on adherence is significant as non-adherence is associated with higher rates of disease relapses and irreversible MS progression [69]. As well as adherence, treatment persistence is an important factor for any first-line injectable therapy if patients are to benefit from early intervention. A recent Australian study of treatment persistence in RRMS patients found that the median duration of a first-line DMT was 2.5 years [interquartile range (IQR) 1.0-6.7, $n=771$ ] [71]. By therapy, the median duration of persistence was 1.7 years for GA (IQR $0.62-5.2, n=117), 2.6$ years for IFN beta-1a IM (IQR 1.2-8.5, $n=153$ ), 2.5 years for IFN beta-1a SC (IQR 0.70-7.1, $n=220$ ) and 2.8 years for IFN beta-1b (IQR 1.0-5.8, $n=270$ ). Unadjusted 
and adjusted analyses indicated that patients receiving GA as first-line DMT discontinued treatment at a greater rate than patients receiving IFN beta-1a IM (HR 1.74; $P=0.001$, adjusted analysis), IFN beta-1a SC (HR 1.40; $P=0.03)$ and IFN beta-1b (HR 1.47; $P=0.01)$.

\section{ADVANTAGES AND EVOLUTION OF AUTOINJECTION DEVICES}

Self-injection can be inconvenient, uncomfortable, and daunting for many patients; these factors should be taken into account when considering long-term therapy $[19,20]$. Autoinjectors simplify and standardize the treatment-administration process, improve treatment satisfaction and convenience for patients, reduce the number and severity of ISRs, and are associated with high levels of adherence compared with manual self-injection [17, 20, 72, 73]. Trypanophobia is common [20], but may be countered by the fact that needles are hidden from view in most autoinjection devices [72]. Importantly, many patients prefer autoinjection to conventional manual selfinjection [19, 72]. Such considerations are important, because they make patients more likely to adopt and adhere to therapy [19]. In a prospective, observational study involving 76 patients with RRMS receiving IFN beta-1a $44 \mu \mathrm{g}$ three times weekly using an autoinjector, 80.3\% of patients were satisfied with treatment [19]. The advantages of using an autoinjector reported by patients included convenience $(53 \%)$, ease of use (25\%), less psychological trauma and pain, and fewer ISRs $(11 \%, 6 \%$, and $5 \%$, respectively). In a survey of 201 patients with RRMS, reliability was considered the most important feature of autoinjectors, followed by convenience (e.g., ease of use, one-handed operation, and ability to reach injection sites) [21]; devices that permit one-handed injection, at sites that are normally out of reach, mitigate the over-use of more accessible injection sites, and thus should reduce skin lesions [21, 72].

Patient-reported compliance and satisfaction with IFN beta-1b treatment using an autoinjector was also assessed in a prospective, 12-week, European real-world observational study (EXCELLENT) conducted in 582 patients [20]. Over the study period, $96.5 \%$ of patients were compliant with treatment. Compared with baseline, increased scores were observed in the Treatment Satisfaction Questionnaire for Medication-9 convenience domain between weeks 6 and $12(P=0.0009)$, and in the 5-dimension European Quality of Life questionnaire between baseline and week 12 $(P<0.0001)$, demonstrating improvements in patient convenience and health-related quality of life, respectively. There were also nonsignificant increases in global satisfaction and effectiveness scores. Finally, the prospective, observational 2-year BetaPlus (ClinicalTrials.gov \#NCT01233245) study explored the influence of patient supportive strategies (including autoinjectors, web-based information, a text-based injection/refill reminder service, and an interactive patientphysician program) on adherence in 1,077 patients with RRMS or SPMS who had switched to IFN beta- $1 \mathrm{~b}$ in the previous 1-3 months [73]. Of the strategies tested, autoinjector use was found to be the strongest predictor of treatment adherence.

\section{CONSIDERATIONS WHEN SELECTING IFN BETA-1b TREATMENT}

Probably the most common reasons supporting the selection of IFN beta-1b are its long history of safe use and the efficacy of high-dose highfrequency therapy. Disease stage may also be a 
consideration given the evidence that IFN beta$1 \mathrm{~b}$ delayed conversion to CDMS among patients experiencing CIS; it is also a treatment option to consider later in the disease course, in relapsing SPMS, given the reduction in relapse rates observed during phase 3 trials $[8,36]$, and the lower risk of disability progression subsequently determined across these trials [39]. IFN beta-1b can be used as a de-escalation option to reduce the likelihood of certain side-effects associated with long-term use of more aggressive therapies although further studies are warranted [74]. Patients' comorbidities will be considered, for example, where liver function is compromised, and the age of the patient may also be a factor, such as in women of childbearing potential for whom new oral therapies may be contraindicated or lacking precedent for safe use. Patients' preferences and lifestyles are also critical to therapy selection, because treatmentrelated clinical benefits depend upon patients' adherence. Any of the injectable therapies may be a difficult choice to make for patients with trypanophobia, but support, suitable devices for self-administration and knowledge of the effectiveness of the therapy can reduce these concerns to manageable levels.

Ultimately, it is often the case that therapy will have to be reconsidered, either because of adherence/tolerability issues, or because of disease breakthrough (disability progression, relapses, MRI lesion activity). Historically, the options available under these circumstances were the BRACE therapies, but the advent of oral and intravenous treatments has broadened these options considerably. Adherence and tolerability issues are probably more readily addressed than disease breakthrough because the combination of indication, posology and side-effect profile will often limit the choice of next-line therapy. Regarding disease breakthrough, two overarching challenges are faced by neurologists: first, how to judge what level of disease breakthrough merits a change of treatment, particularly if the patient is accustomed to and comfortable with their existing therapy; and second, whether to escalate therapy. The nature of the MS disease course dictates that while the chosen therapy must slow or ideally prevent further disease progression, allowance must be made for the fact that treatment is life-long. However, the overall goal is to achieve freedom from disease.

\section{CONCLUSION}

Here, we have reviewed the clinical evidence associated with IFN beta-1b in the treatment of MS. In addition, improvements in delivery systems have greatly improved patients' satisfaction with and adherence to therapy, compared with traditional manual injection. Notwithstanding the recent expansion in therapeutic options, the well-established efficacy, safety, and tolerability profiles continue to support the long-term use of IFN beta-1b, both early in the disease course and later in the progressive stages of disease.

\section{ACKNOWLEDGMENTS}

Both named authors meet the ICMJE criteria for authorship for this manuscript, take responsibility for the integrity of the work as a whole, and have given final approval for the version to be published. The authors would like to acknowledge Jeremy Bright from Oxford PharmaGenesis $^{\mathrm{TM}}$ Ltd, who provided editorial support with funding from Novartis Pharma AG. Publication fees were paid by Novartis Pharma AG. 
Conflict of interest. Martin Marziniak has received lecture fees, travel grants and fees for consulting from: Bayer Health Care AG, Beiersdorf AG, Biogen Idec GmbH, Merck KGaAO, Novartis Pharma GmbH, Pfizer Pharma GmbH, Sanofi-Aventis (Genzyme), and Teva. Sven Meuth has received honoraria for lecturing and travel expenses for attending meetings and has received financial research support from Bayer, Bayer Schering, Biogen Idec, Genzyme, Merck Serono, MSD, Novartis, Novo Nordisk, Sanofi-Aventis, and Teva.

Compliance with ethics guidelines. This review article is based on previously conducted studies, and does not involve any new studies of human or animal subjects performed by any of the authors.

Open Access. This article is distributed under the terms of the Creative Commons Attribution Noncommercial License which permits any noncommercial use, distribution, and reproduction in any medium, provided the original author(s) and the source are credited.

\section{REFERENCES}

1. Compston A, Coles A. Multiple sclerosis. Lancet. 2008;372:1502-17.

2. Lublin FD, Reingold SC, Cohen JA, et al. Defining the clinical course of multiple sclerosis: the 2013 revisions. Neurology. 2014;83:278-86.

3. Lublin F. History of modern multiple sclerosis therapy. J Neurol. 2005;252(Suppl 3):iii3-iii9.

4. Schwid SR, Panitch HS. Full results of the evidence of interferon dose-response-European North American comparative efficacy (EVIDENCE) study: a multicenter, randomized, assessor-blinded comparison of low-dose weekly versus high-dose, high-frequency interferon beta-1a for relapsing multiple sclerosis. Clin Ther. 2007;29:2031-48.
5. Kappos L, Freedman MS, Polman CH, et al. Effect of early versus delayed interferon beta- $1 \mathrm{~b}$ treatment on disability after a first clinical event suggestive of multiple sclerosis: a 3-year follow-up analysis of the BENEFIT study. Lancet. 2007;370:389-97.

6. Kappos L, Polman CH, Freedman MS, et al. Treatment with interferon beta- $1 \mathrm{~b}$ delays conversion to clinically definite and McDonald MS in patients with clinically isolated syndromes. Neurology. 2006;67:1242-9.

7. Jacobs LD, Beck RW, Simon JH, et al. Intramuscular interferon beta-1a therapy initiated during a first demyelinating event in multiple sclerosis. CHAMPS Study Group. N Engl J Med. 2000;343:898-904.

8. European Study Group on Interferon Beta-1b in Secondary Progressive MS. Placebo-controlled multicentre randomised trial of interferon beta- $1 \mathrm{~b}$ in treatment of secondary progressive multiple sclerosis. Lancet. 1998;352:1491-7.

9. Secondary Progressive Efficacy Clinical Trial of Recombinant Interferon-beta-1a in MS (SPECTRIMS) Study Group. Randomized controlled trial of interferon-beta-1a in secondary progressive MS: clinical results. Neurology. 2001;56:1496-504.

10. Cohen JA, Cutter GR, Fischer JS, et al. Benefit of interferon beta-1a on MSFC progression in secondary progressive MS. Neurology. 2002;59:679-87.

11. Comi G, Filippi M, Barkhof F, et al. Effect of early interferon treatment on conversion to definite multiple sclerosis: a randomised study. Lancet. 2001;357:1576-82.

12. Comi G, Martinelli V, Rodegher M, et al. Effect of glatiramer acetate on conversion to clinically definite multiple sclerosis in patients with clinically isolated syndrome (PreCISe study): a randomised, double-blind, placebo-controlled trial. Lancet. 2009;374:1503-11.

13. Khan O, Rieckmann P, Boyko A, Selmaj K, Zivadinov R. Three times weekly glatiramer acetate in relapsing-remitting multiple sclerosis. Ann Neurol. 2013;73:705-13.

14. Meuth SG, Gobel K, Wiendl H. Immune therapy of multiple sclerosis-future strategies. Curr Pharm Des. 2012;18:4489-97.

15. Burks J. Interferon-beta1b for multiple sclerosis. Expert Rev Neurother. 2005;5:153-64.

16. Hartung HP. High-dose, high-frequency recombinant interferon beta-1a in the treatment 
of multiple sclerosis. Expert Opin Pharmacother. 2009;10:291-309.

17. Brochet B, Lemaire G, Beddiaf A. Reduction of injection site reactions in multiple sclerosis (MS) patients newly started on interferon beta $1 \mathrm{~b}$ therapy with two different devices. Rev Neurol (Paris). 2006;162:735-40.

18. Girouard N, Theoret G. Management strategies for improving the tolerability of interferons in the treatment of multiple sclerosis. Can J Neurosci Nurs. 2008;30:18-25.

19. Lugaresi A, Durastanti V, Gasperini C, et al. Safety and tolerability in relapsing-remitting multiple sclerosis patients treated with high-dose subcutaneous interferon-beta by Rebiject autoinjection over a 1-year period: the CoSa study. Clin Neuropharmacol. 2008;31:167-72.

20. Boeru G, Milanov I, De Robertis F, et al. ExtaviJect(R) 30G device for subcutaneous selfinjection of interferon beta-1b for multiple sclerosis: a prospective European study. Med Devices (Auckl). 2013;6:175-84.

21. Thakur K, Manuel L, Tomlinson M. Autoinjectors for administration of interferon beta-1b in multiple sclerosis: patient preferences and the ExtaviPro ${ }^{\mathrm{TM}}$ $30 \mathrm{G}$ and Betacomfort ${ }^{\circledR}$ devices. Pragmat Obs Res. 2013;4:19-26.

22. Department of Health and Human Services. Interferon beta-1b-approval Letter, 23 July 1993. http://www.accessdata.fda.gov/drugsatfda_docs/ nda/pre96/103471s0000_APPROV.pdf. Accessed 27 June 2014 .

23. European Medicines Agency. Betaferon-European Public Assessment Report: summary for the public, May 2012. http://www.ema.europa.eu/docs/en_GB/ document_library/EPAR_-_Summary_for_the_public/ human/000081/WC500053086.pdf. Accessed 27 June 2014 .

24. Reder AT, Ebers GC, Traboulsee A, et al. Crosssectional study assessing long-term safety of interferon-beta-1b for relapsing-remitting MS. Neurology. 2010;74:1877-85.

25. European Medicines Agency. Extavia ${ }^{\circledR}$ - summary of product characteristics, 20 May 2013. http:// www.ema.europa.eu/docs/en_GB/document_library/ EPAR_-_Product_Information/human/000933/WC 500034701.pdf. Accessed 27 June 2014.

26. McDonald WI, Compston A, Edan G, et al. Recommended diagnostic criteria for multiple sclerosis: guidelines from the International Panel on the diagnosis of multiple sclerosis. Ann Neurol. 2001;50:121-7.
27. Poser CM, Paty DW, Scheinberg L, et al. New diagnostic criteria for multiple sclerosis: guidelines for research protocols. Ann Neurol. $1983 ; 13: 227-31$.

28. Edan G, Kappos L, Montalban X, et al. Long-term impact of interferon beta-1b in patients with CIS: 8-year follow-up of BENEFIT. J Neurol Neurosurg Psychiatry. 2013. doi:10.1136/jnnp-2013-306222 (Epub ahead of print).

29. The IFNB Multiple Sclerosis Study Group. Interferon beta-1b is effective in relapsingremitting multiple sclerosis. I. Clinical results of a multicenter, randomized, double-blind, placebocontrolled trial. Neurology. 1993;43:655-61.

30. Paty DW, Li DK. Interferon beta-1b is effective in relapsing-remitting multiple sclerosis. II. MRI analysis results of a multicenter, randomized, double-blind, placebo-controlled trial. UBC MS/ MRI Study Group and the IFNB Multiple Sclerosis Study Group. Neurology. 1993;43:662-7.

31. Goodin DS, Traboulsee A, Knappertz V, 16-year Long Term Follow-up Study Investigators, et al. Relationship between early clinical characteristics and long term disability outcomes: 16 year cohort study (follow-up) of the pivotal interferon $\beta$ - $1 b$ trial in multiple sclerosis. J Neurol Neurosurg Psychiatry. 2012;83:282-7.

32. Goodin DS, Reder AT, Ebers GC, et al. Survival in MS: a randomized cohort study 21 years after the start of the pivotal IFNbeta-1b trial. Neurology. 2012;78:1315-22.

33. Torkildsen GN, Lie SA, Aarseth JH, Nyland H, Myhr KM. Survival and cause of death in multiple sclerosis: results from a 50-year follow-up in Western Norway. Mult Scler. 2008;14:1191-8.

34. Ebers GC, Traboulsee A, Li D, et al. Analysis of clinical outcomes according to original treatment groups 16 years after the pivotal IFNB-1b trial. J Neurol Neurosurg Psychiatry. 2010;81:907-12.

35. Goodin DS, Ebers GC, Cutter G, et al. Cause of death in MS: long-term follow-up of a randomised cohort, 21 years after the start of the pivotal IFNbeta-1b study. BMJ Open. 2012;2:e001972. doi:10.1136/bmjopen-2012-001972.

36. Panitch H, Miller A, Paty D, Weinshenker B. Interferon beta-1b in secondary progressive MS: results from a 3 -year controlled study. Neurology. 2004;63:1788-95.

37. Kappos L, Polman C, Pozzilli C, et al. Final analysis of the European multicenter trial on IFNbeta-1b in secondary-progressive MS. Neurology. 2001;57:1969-75. 
38. Miller DH, Molyneux PD, Barker GJ, et al. Effect of interferon-beta1b on magnetic resonance imaging outcomes in secondary progressive multiple sclerosis: results of a European multicenter, randomized, double-blind, placebo-controlled trial. European Study Group on Interferon-beta1b in secondary progressive multiple sclerosis. Ann Neurol. 1999;46:850-9.

39. Kappos L, Weinshenker B, Pozzilli C, et al. Interferon beta-1b in secondary progressive MS: a combined analysis of the two trials. Neurology. 2004;63:1779-87.

40. Durelli L, Verdun E, Barbero P, et al. Every-otherday interferon beta-1b versus once-weekly interferon beta-1a for multiple sclerosis: results of a 2-year prospective randomised multicentre study (INCOMIN). Lancet. 2002;359:1453-60.

41. Koch-Henriksen N, Sorensen PS, Christensen T, et al. A randomized study of two interferon-beta treatments in relapsing-remitting multiple sclerosis. Neurology. 2006;66:1056-60.

42. Etemadifar M, Janghorbani $M$, Shaygannejad V. Comparison of Betaferon, Avonex, and Rebif in treatment of relapsing-remitting multiple sclerosis. Acta Neurol Scand. 2006;113:283-7.

43. O'Connor P, Filippi M, Arnason B, et al. $250 \mu \mathrm{g}$ or $500 \mu \mathrm{g}$ interferon beta-1b versus $20 \mathrm{mg}$ glatiramer acetate in relapsing-remitting multiple sclerosis: a prospective, randomised, multicentre study. Lancet Neurol. 2009;8:889-97.

44. Cadavid D, Wolansky LJ, Skurnick J, et al. Efficacy of treatment of MS with IFNbeta-1b or glatiramer acetate by monthly brain MRI in the BECOME study. Neurology. 2009;72:1976-83.

45. Filippini G, Del Giovane C, Vacchi L, et al. Immunomodulators and immunosuppressants for multiple sclerosis: a network meta-analysis. Cochrane Database Syst Rev. 2013;6:CD008933.

46. Filippi M, Rocca MA, Camesasca F, et al. Interferon beta- $1 \mathrm{~b}$ and glatiramer acetate effects on permanent black hole evolution. Neurology. 2011;76:1222-8.

47. Cadavid D, Cheriyan J, Skurnick J, et al. New acute and chronic black holes in patients with multiple sclerosis randomised to interferon beta- $1 \mathrm{~b}$ or glatiramer acetate. J Neurol Neurosurg Psychiatry. 2009;80:1337-43.

48. US Food and Drug Administration. Extavia ${ }^{\circledR}$ prescribing information. 2012. https://www. pharma.us.novartis.com/product/pi/pdf/extavia.pdf. Accessed 27 June 2014.
49. Creeke PI, Farrell RA. Clinical testing for neutralizing antibodies to interferon-beta in multiple sclerosis. Ther Adv Neurol Disord. 2013;6:3-17.

50. Goodin DS, Hartung HP, O'Connor $\mathrm{P}$, et al. Neutralizing antibodies to interferon beta- $1 \mathrm{~b}$ multiple sclerosis: a clinico-radiographic paradox in the BEYOND trial. Mult Scler. 2012;18:181-95.

51. Wingerchuk DM, Carter JL. Multiple sclerosis: current and emerging disease-modifying therapies and treatment strategies. Mayo Clin Proc. 2014;89:225-40.

52. Havrdova E, Galetta S, Hutchinson M, et al. Effect of natalizumab on clinical and radiological disease activity in multiple sclerosis: a retrospective analysis of the Natalizumab Safety and Efficacy in Relapsing-Remitting Multiple Sclerosis (AFFIRM) study. Lancet Neurol. 2009;8:254-60.

53. US Food and Drug Administration. Aubagio ${ }^{\circledR}$ prescribing information. http://www.accessdata. fda.gov/drugsatfda_docs/label/2012/202992s000lbl. pdf. Accessed 27 June 2014.

54. Oh J, O'Connor PW. An update of teriflunomide for treatment of multiple sclerosis. Ther Clin Risk Manag. 2013;9:177-90.

55. US Food and Drug Administration. Tecfidera ${ }^{\circledR}$ prescribing information. http://www.accessdata. fda.gov/drugsatfda_docs/label/2013/204063lbl.pdf. Accessed 27 June 2014.

56. Fox RJ, Kita M, Cohan SL, et al. BG-12 (dimethyl fumarate): a review of mechanism of action, efficacy, and safety. Curr Med Res Opin. 2014;30:251-62.

57. European Medicines Agency. Tecfidera ${ }^{\circledR}$ — summary of opinion. http://www.ema.europa.eu/docs/en GB/document_library/EPAR_-_Product_Information/ human/002601/WC500162069.pdf. Accessed 27 June 2014.

58. Maddison P, Kiely P, Kirkham B, et al. Leflunomide in rheumatoid arthritis: recommendations through a process of consensus. Rheumatology (Oxford). 2005;44:280-6.

59. Noseworthy JH, Wolinsky JS, Lublin FD, et al. Linomide in relapsing and secondary progressive MS: part I: trial design and clinical results. North American Linomide Investigators. Neurology. 2000;54:1726-33.

60. O'Connor P, Wolinsky JS, Confavreux C, et al. Randomized trial of oral teriflunomide for relapsing multiple sclerosis. New Engl J Med. 2011;365:1293-303. 
61. Confavreux C, O'Connor P, Comi G, et al. Oral teriflunomide for patients with relapsing multiple sclerosis (TOWER): a randomised, double-blind, placebo-controlled, phase 3 trial. Lancet Neurol. 2014;13:247-56.

62. Vermersch P, Czlonkowska A, Grimaldi LM, et al. Teriflunomide versus subcutaneous interferon beta$1 \mathrm{a}$ in patients with relapsing multiple sclerosis: a randomised, controlled phase 3 trial. Mult Scler. 2014;20:705-16.

63. Gold R, Kappos L, Arnold DL, et al. Placebocontrolled phase 3 study of oral BG-12 for relapsing multiple sclerosis. New Engl J Med. 2012;367:1098-107.

64. Fox RJ, Miller DH, Phillips JT, et al. Placebocontrolled phase 3 study of oral BG-12 or glatiramer in multiple sclerosis. New Engl J Med. 2012;367:1087-97.

65. Baum K, O'Leary C, Coret Ferrer F, et al. Comparison of injection site pain and injection site reactions in relapsing-remitting multiple sclerosis patients treated with interferon beta-1a or 1b. Mult Scler. 2007;13:1153-60.

66. Harris C, Billisberger K, Tillotson L, et al. Injectionsite pain in patients with multiple sclerosis: interferon beta- $1 \mathrm{~b}$ versus interferon beta-1a. Int J MS Care. 2005/2006;7:132-6.

67. Portaccio E, Amato MP. Improving compliance with interferon-beta therapy in patients with multiple sclerosis. CNS Drugs. 2009;23:453-62.
68. Agashivala N, Wu N, Abouzaid S, et al. Compliance to fingolimod and other disease modifying treatments in multiple sclerosis patients, a retrospective cohort study. BMC Neurol. 2013;13:138.

69. Menzin J, Caon C, Nichols C, et al. Narrative review of the literature on adherence to disease-modifying therapies among patients with multiple sclerosis. J Manag Care Pharm. 2013;19:S24-40.

70. Tremlett HL, Oger J. Interrupted therapy: stopping and switching of the beta-interferons prescribed for MS. Neurology. 2003;61:551-4.

71. Jokubaitis VG, Spelman T, Lechner-Scott J, et al. The Australian Multiple Sclerosis (MS) immunotherapy study: a prospective, multicentre study of drug utilisation using the MSBase platform. PLoS One. 2013;8:e59694.

72. Kozubski W. Autoinjector improves injectionrelated tolerability issues in patients with multiple sclerosis-exploring the new ExtaviJect ${ }^{\mathrm{TM}}$ 30G system for the injection of interferon beta-1b. Eur Neurol Rev. 2010;5:77-81.

73. Pozzilli C, Schweikert B, Ecari U, Oentrich W. Supportive strategies to improve adherence to IFN beta-1b in multiple sclerosis-results of the betaPlus observational cohort study. J Neurol Sci. 2011;307:120-6.

74. Gobbi C, Meier DS, Cotton F, et al. Interferon beta $1 \mathrm{~b}$ following natalizumab discontinuation: one year, randomized, prospective, pilot trial. BMC Neurol. 2013;13:101. 